Portland State University

PDXScholar

\title{
Evaluating Hourly Rainfall Characteristics over the U.S. Great Plains in Dynamically Downscaled Climate Model Simulations using NASA-Unified WRF
}

Huikyo Lee

NASA Jet Propulsion Laboratory

Duane E. Waliser

NASA Jet Propulsion Laboratory

Robert Ferraro

NASA Jet Propulsion Laboratory

Takamichi Iguchi

University of Maryland at College Park

Christa D. Peters-Lidard

NASA Goddard Space Flight Center

Follow this and additional works at: https://pdxscholar.library.pdx.edu/geog_fac

ePraxtopabe fanadoditienia/suithorss Commons, Environmental Monitoring Commons, and the Physical and Environmental Geography Commons

Let us know how access to this document benefits you.

\section{Citation Details}

Lee, H., Waliser, D. E., Ferraro, R., Iguchi, T., Peters-Lidard, C. D., Tian, B., ... \& Wright, D. B. (2017).

Evaluating hourly rainfall characteristics over the US Great Plains in dynamically downscaled climate model simulations using NASA-Unified WRF (NU-WRF). Journal of Geophysical Research: Atmospheres.

This Article is brought to you for free and open access. It has been accepted for inclusion in Geography Faculty Publications and Presentations by an authorized administrator of PDXScholar. Please contact us if we can make this document more accessible: pdxscholar@pdx.edu. 


\section{Authors}

Huikyo Lee, Duane E. Waliser, Robert Ferraro, Takamichi Iguchi, Christa D. Peters-Lidard, Baijun Tian, Paul C. Loikith, and Daniel B. Wright 


\section{Warning Concerning Copyright Restrictions}

The copyright law of the United States (Title 17, United States Code) governs the making of photocopies or other reproductions of copyrighted material. Under certain conditions specified in the law, libraries and archives are authorized to furnish a photocopy or other reproduction. One of these specific conditions is that the photocopy or reproduction is not to be "used for any purpose other than private study, scholarship, or research." If a user makes a request for, or later uses, a photocopy or reproduction for purposes in excess of "fair use," that user may be liable for copyright infringement.

This institution reserves the right to refuse to accept a copying order if, in its judgment, fulfillment of the order would involve violation of copyright law. 
Journal of Geophysical Research: Atmospheres

\section{RESEARCH ARTICLE}

10.1002/2017JD026564

\section{Key Points:}

- NASA-Unified WRF simulations were performed at three different horizontal resolutions $(4,12$, and $24 \mathrm{~km}$ ) over the contiguous United States

- The added value of high-resolution simulations is realistic rainfall characteristics in the Great Plains during summer

- Without temporal overlap for the entire period with observations, the added value of high-resolution simulations can be demonstrated

Correspondence to:

H. Lee,

huikyo.lee@jpl.nasa.gov

Citation:

Lee, H., D. E. Waliser, R. Ferraro, T. Iguchi, C. D. Peters-Lidard, B. Tian, P. C. Loikith, and D. B. Wright (2017), Evaluating hourly rainfall characteristics over the U.S. Great Plains in dynamically downscaled climate model simulations using NASA-Unified WRF, J. Geophys. Res. Atmos., 122, 7371-7384, doi:10.1002/ 2017JD026564

Received 27 JAN 2017 Accepted 26 JUN 2017 Accepted article online 30 JUN 2017 Published online 21 JUL 2017

(O2017. American Geophysical Union. All Rights Reserved.

\section{Evaluating hourly rainfall characteristics over the U.S. Great Plains in dynamically downscaled climate model simulations using NASA-Unified WRF}

\author{
Huikyo Lee ${ }^{1}$ (D) , Duane E. Waliser ${ }^{1}(\mathbb{D})$, Robert Ferraro' ${ }^{1}$, Takamichi Iguchi ${ }^{2,3}$, \\ Christa D. Peters-Lidard ${ }^{3}$, Baijun Tian' ${ }^{\text {(D) , Paul C. Loikith }}{ }^{4}$, and Daniel B. Wright ${ }^{5}$ \\ ${ }^{1}$ Jet Propulsion Laboratory, California Institute of Technology, Pasadena, California, USA, ${ }^{2}$ Earth System Science \\ Interdisciplinary Center, University of Maryland, College Park, Maryland, USA, ${ }^{3}$ NASA Goddard Space Flight Center, \\ Greenbelt, Maryland, USA, ${ }^{4}$ Department of Geography, Portland State University, Portland, Oregon, USA, ${ }^{5}$ Civil and \\ Environmental Engineering, University of Wisconsin-Madison, Madison, Wisconsin, USA
}

Abstract Accurate simulation of extreme precipitation events remains a challenge in climate models. This study utilizes hourly precipitation data from ground stations and satellite instruments to evaluate rainfall characteristics simulated by the NASA-Unified Weather Research and Forecasting (NU-WRF) regional climate model at horizontal resolutions of 4, 12, and $24 \mathrm{~km}$ over the Great Plains of the United States. We also examined the sensitivity of the simulated precipitation to different spectral nudging approaches and the cumulus parameterizations. The rainfall characteristics in the observations and simulations were defined as an hourly diurnal cycle of precipitation and a joint probability distribution function (JPDF) between duration and peak intensity of precipitation events over the Great Plains in summer. We calculated a JPDF for each data set and the overlapping area between observed and simulated JPDFs to measure the similarity between the two JPDFs. Comparison of the diurnal precipitation cycles between observations and simulations does not reveal the added value of high-resolution simulations. However, the performance of NU-WRF simulations measured by the JPDF metric strongly depends on horizontal resolution.

The simulation with the highest resolution of $4 \mathrm{~km}$ shows the best agreement with the observations in simulating duration and intensity of wet spells. Spectral nudging does not affect the JPDF significantly. The effect of cumulus parameterizations on the JPDFs is considerable but smaller than that of horizontal resolution. The simulations with lower resolutions of 12 and $24 \mathrm{~km}$ show reasonable agreement but only with the high-resolution observational data that are aggregated into coarse resolution and spatially averaged.

\section{Introduction}

Under a warming climate, extreme precipitation and drought events are expected to occur more frequently [Ban et al., 2015; Donat et al., 2016]. The spatial pattern of extreme precipitation and its change are highly heterogeneous, so it is important to study regional characteristics and variability of extreme precipitation using observational and model data sets. Previous studies [e.g., Karl and Knight, 1998; Kunkel et al., 2003; Groisman et al., 2012] have shown observational evidence for increasing extreme precipitation over the contiguous United States (CONUS). Although an understanding of extreme precipitation and related human influences at a local/regional scale is vital for policy decision making, extreme precipitation across the CONUS is not well represented in global climate models (GCMs). For example, Min et al. [2011] show that the Coupled Model Intercomparison Project Phase 3 (CMIP3) GCMs tend to underestimate the observed trends in extreme precipitation over the CONUS. The recent fifth phase of the Coupled Model Intercomparison Project (CMIP5) GCMs also exhibit weaker trends in extreme precipitation for CONUS than those in the observations with large model-to-model variability [Janssen et al., 2014]. As spatial resolution of climate models becomes finer, the models generally better represent extreme weather events [e.g., Lee et al., 2014a; Lee and Hong, 2014], the hydrological cycle [e.g., Lee et al., 2014b; J. W. Lee et al., 2015], and influential land surface processes [e.g., De Sales and Xue, 2011, Lucas-Picher et al., 2012]. To demonstrate the importance of fine spatial resolution in climate simulations, regional climate model (RCM) simulations have been evaluated against observations and compared with relatively low-resolution simulations from GCMs [Leung et al., 2003; Laprise et al., 2008; 
Feser et al., 2011; Hong and Kanamitsu, 2014]. Di Luca et al. [2012] show that RCMs represent short-term precipitation in warm seasons better than GCMs over North America. Dynamical downscaling using RCMs can improve representation of topography and related processes in addition to explicit numerical computation of dynamical and physical processes [Hall, 2014]. Maraun et al. [2010] and Wehner [2013] also report that realistic precipitation in coastal areas and regions with complicated topography is the advantage of high-resolution RCM simulations. Higher spatial resolution may further improve the performance of RCMs. Pieri et al. [2015] and Casanueva et al. [2016] show that the high-resolution RCM simulations reduce precipitation biases compared to their low-resolution counterparts. Several studies [Chan et al., 2014; Kendon et al., 2012, 2014] demonstrate that the United Kingdom Met Office RCM, which has very high spatial resolution of $1.5 \mathrm{~km}$, simulates rainfall characteristics better than coarse-resolution simulations using the same model.

Relatively few studies have focused on high-resolution RCMs' performance in simulating precipitation over flat topography where even low-resolution GCMs are expected to simulate precipitation reasonably. However, contrary to expectations, Harding et al. [2013] show that dynamically downscaled CMIP5 simulations at 30 and $10 \mathrm{~km}$ resolutions reproduce diurnal cycle and extreme precipitation better than the original CMIP5 output over the Central U.S. where local topography does not significantly influence precipitation. Along with the continuous efforts to generate climate projections with higher resolutions, RCMs require evaluation studies that can highlight the added value of high spatial resolution and the associated improvements in simulations other than the improved topographical precipitation. Furthermore, the spatial resolution of around $10 \mathrm{~km}$ in the previous studies is not high enough to fully utilize observations with spatial resolutions finer than $10 \mathrm{~km}$.

The main objective of the current study is to demonstrate the advantages of running an RCM at the very high-resolution of $4 \mathrm{~km}$ in simulating rainfall characteristics over flat topography. Extreme precipitation is frequently observed over the central U.S. during summer [Janssen et al., 2016]. Thus, we focus on evaluating simulated rainfall characteristics over the Great Plains in summer (from June through August) using two observed precipitation data sets from ground-based stations and satellite instruments.

The paper is organized as follows. Section 2 describes the observational and model data sets used. Section 3 presents the diagnostic of hourly precipitation and a model evaluation metric to show the added value of high-resolution simulations. Section 4 reports a comparison between the observations and models. Results of this study are summarized in section 5 .

\section{Data and Model}

Table 1 summarizes the observational and model data sets for surface precipitation used in the current study. The National Centers for Environmental Prediction Stage IV data [Lin, 2011] are based on radar and gauge observations at ground stations over CONUS. Integrated Multi-satellitE Retrievals for Global Precipitation Measurement (GPM IMERG, hereafter GPM) data [Huffman et al., 2015] provide precipitation products based on multiple satellites and ground gauges. The original temporal resolution of GPM IMERG is a half hour, but we generated hourly precipitation data sets to make it comparable to the other data sets. The spatial resolutions of Stage IV and GPM are $4 \mathrm{~km}$ and $0.1^{\circ}$, respectively.

We used the high-resolution simulation results of the NASA-Unified Weather Research and Forecasting (NU-WRF) [Peters-Lidard et al., 2015] over CONUS for multiple years in the 2000s managed in NASA's downscaling project [Ferraro et al., 2017; Iguchi et al., 2017; Kim et al., 2017]. NU-WRF is a NASA-oriented superset of the Advanced Research WRF (WRF-ARW) model [Skamarock et al., 2008]. The model has multiple modeling components, such as improved land surface initialization and microphysics scheme, specially developed by NASA Goddard Space Flight Center, in addition to the standard package in WRF-ARW. In the NASA's downscaling project, NU-WRF used the Goddard cumulus ensemble (GCE) single-moment, three-ice bulk microphysics scheme [Tao et al., 2003; Lang et al., 2007] for the grid-scale cloud microphysics and Goddard shortwave and longwave radiation schemes [Chou and Suarez, 1999, 2001] for calculating radiative flux. Also, the NU-WRF simulations used improved initial soil properties obtained from the NASA Land Information System (LIS) model [Kumar et al., 2006].

So far, the performance of NU-WRF has been evaluated in case studies based on relatively short-term simulations compared with observations. The unique coupling between LIS and WRF improves land initialization and surface flux parameterization, and forecast of near-surface temperature and humidity [Santanello et al., 2013]. The GCE scheme used in NU-WRF reduces biases in cloud water and graupel [Lang et al., 2011], so that 
Table 1. List of Observations and NU-WRF Simulations ${ }^{a}$

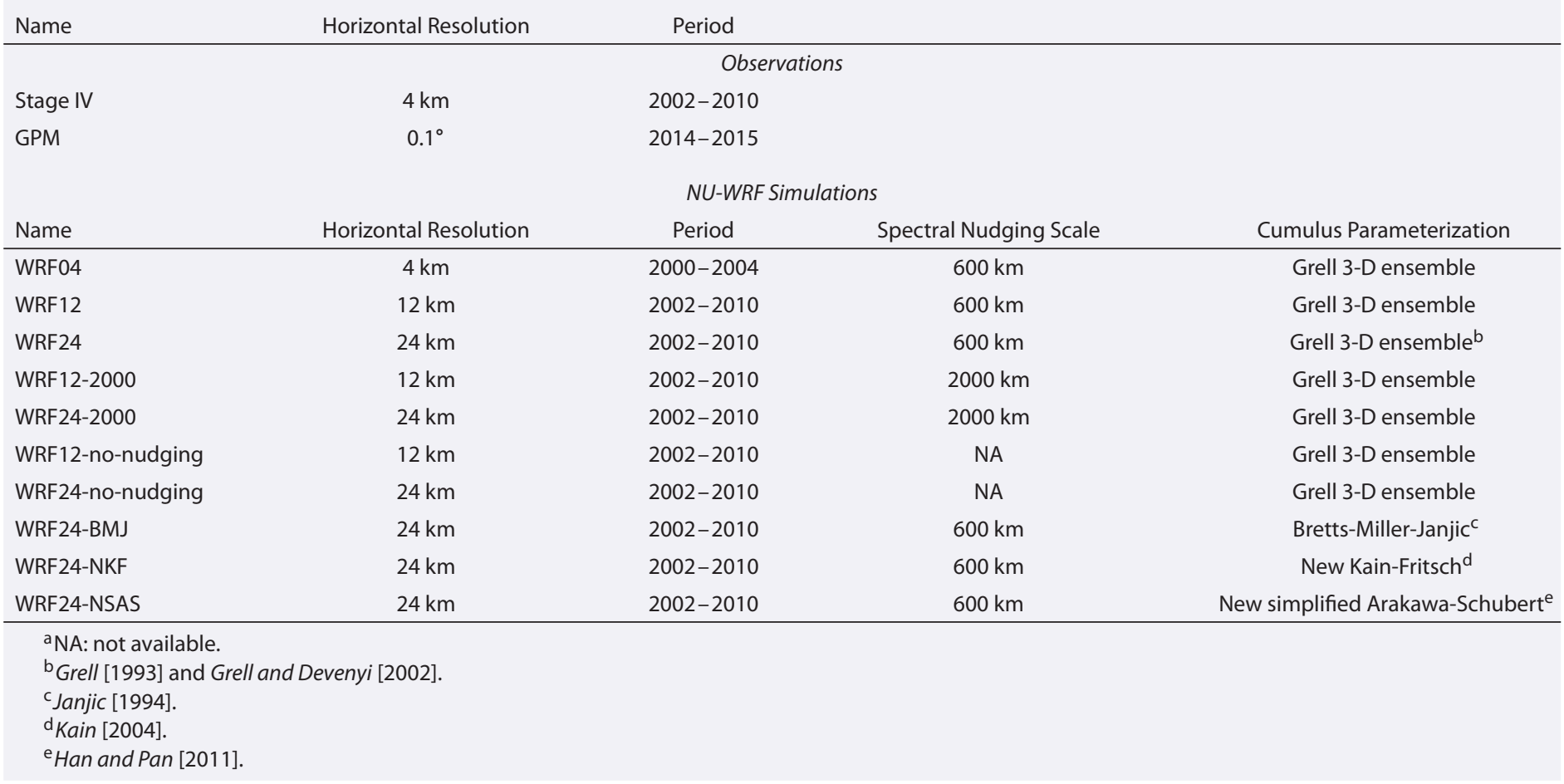

NU-WRF can reasonably predict heavy precipitation in the Great Plains [Tao et al., 2013]. However, its capability as a high-resolution RCM had hardly been investigated before NASA's downscaling project.

To assess the added value of high spatial resolution to NU-WRF simulations, we evaluated simulations forced at the lateral boundaries by the Modern Era Retrospective Analysis for Research and Applications version 2 (MERRA-2) [Bosilovich et al., 2015] with three different horizontal resolutions (24, 12, and $4 \mathrm{~km})$. MERRA-2 is the latest reanalysis data set from NASA's Global Modeling and Assimilation Office with a spatial resolution of $0.5^{\circ}$ (latitude) $\times 0.625^{\circ}$ (longitude). The relatively high spatial resolution of MERRA2 allowed us to perform the default NU-WRF simulations with spectral nudging at $600 \mathrm{~km}$ scale. The simulations at $24 \mathrm{~km}$ and $12 \mathrm{~km}$ resolutions (WRF24 and WRF12) were made for 11 years (2000-2010), whereas the simulation with 4 km resolution (WRF04) is available only for 5 years (2000-2004) due to limited computational resources. We also examined the impact of spectral nudging and cumulus parameterization on the precipitation simulation of NU-WRF. Many previous studies have reported the influence of cumulus parameterizations on rainfall extremes simulated by RCMs [e.g., Cortes-Hernandez et al., 2016; Ji et al., 2014; Pieri et al., 2015]. Included in this evaluation are NU-WRF simulations with spectral nudging at $2000 \mathrm{~km}$ scale (WRF24-2000 and WRF12-2000) and simulations without spectral nudging (WRF24-no-nudging and WRF12-no-nudging). These simulations used the Grell 3-D ensemble scheme [Grell and Devenyi, 2002] for the cumulus parameterization. The Grell 3-D ensemble scheme utilizes a priori solution combining many assumptions commonly applied to cumulus parameterizations and finds the best likelihood solution. We also evaluated three simulations with different cumulus parameterizations (the Betts-Miller-Janjic scheme [Janjic, 1994]: WRF24-BMJ; the new Kain-Fritsch scheme [Kain, 2004]: WRF24-NKF; and the new simplified Arakawa-Schubert scheme [Han and Pan, 2011]: WRF24-NSAS). The deep convection in the BMJ scheme is vertical mixing of heat and moisture to reduce the conditional instability while maintaining the total column enthalpy. The BMJ uses cloud efficiency parameter to characterize different convective regimes. In the NKF scheme, column mass is parameterized with updraft, downdraft, and entrainment to remove the convective available potential energy. The NSAS scheme updates the simplified Arakawa-Schubert scheme by specifying fluxes of heat, moisture, and momentum that are balanced by convective activity. 


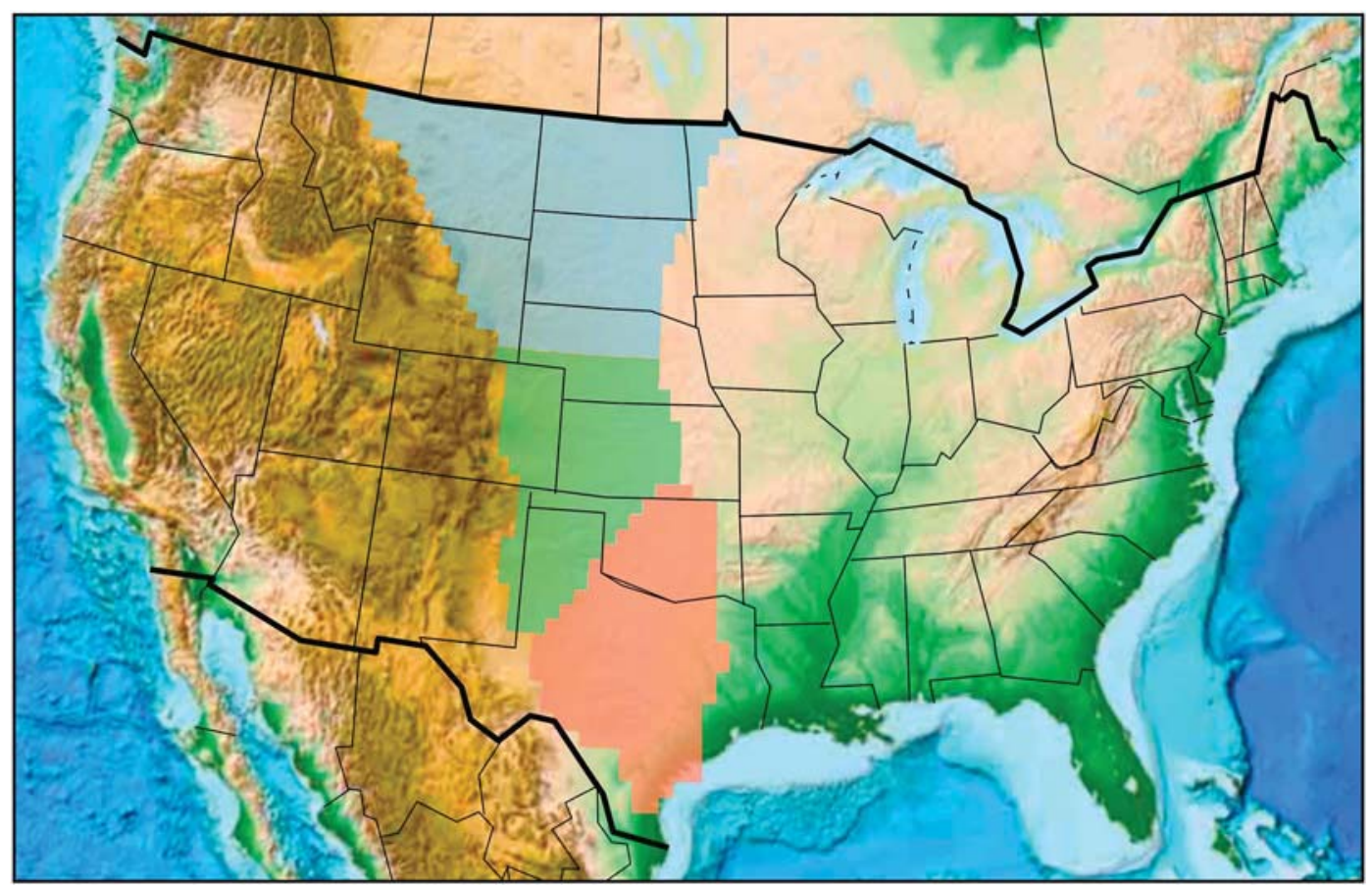

Figure 1. The Northern (blue), Central (green), and Southern (orange) Plains are plotted over the topography map. The three regions are defined in Bukovsky [2011].

\section{Methodology}

In the comparison of rainfall characteristics between the observations and simulations, considering spatial homogeneity of precipitation characteristics is important. Therefore, we analyzed characteristics of hourly precipitation data for the three regions displayed in Figure 1, the Northern, Central, and Southern Plains defined in Bukovsky [2011]. Because the western boundary of the three regions follows the eastern edge of the Rocky Mountains, the regions consist of very flat topography. However, each region's sensitivity to temperature and precipitation variability is different from the others.

Using observational precipitation at daily or 6-hourly time scales, previous studies [e.g., Casanueva et al., 2016; Harding et al., 2013] have shown the improvement of RCM-simulated precipitation with about $10 \mathrm{~km}$ resolution relative to GCMs with coarse resolutions. Nowadays, more hourly precipitation observations are available, so we focus on features in hourly precipitation to demonstrate the potential added value of the $4 \mathrm{~km}$ NU-WRF simulation. As a model evaluation metric to show the value of high-resolution RCM simulations, we adopted a joint probability distribution function (JPDF) between duration and peak intensity of precipitation events from Kendon et al. [2012] and Kendon et al. [2014]. The JPDF reflects regional rainfall characteristics on the subdaily time scale including extremes. By quantifying agreement of simulated JPDFs with those from observations, we evaluated summertime rainfall characteristics in the NU-WRF simulations against the observations.

In defining the JPDF of rainfall intensity and duration, a wet spell is a continuous period of rainfall greater than $0.1 \mathrm{~mm} / \mathrm{h}$ (i.e., every hourly rainfall exceeds $0.1 \mathrm{~mm} / \mathrm{hr}$ within a wet spell). At each grid point in a region, we analyzed hourly time series of precipitation between 1 June and 31 August (JJA) in each year to find wet spells. For this detection of wet spells, we did not spatially regrid the precipitation data sets to maintain fine-scale structures of precipitation patterns. However, we also compared the JPDFs from regridded observation and simulations for reference. The duration and highest hourly rainfall rate of each wet spell are used to bin the event within a JPDF that summarize the region's summertime precipitation characteristics for one summer. This JPDF is essentially a two-dimensional histogram of wet spells binned by peak rainfall rate and duration. Figure 2 shows GPM's JPDF over the Northern Plains for the summer of 2014. The JPDF consists of bins scaling probability (\%) with blue colors for certain ranges of rainfall duration ( $x$ axis) and peak intensity ( $y$ axis). The sum of probability over all the bins is 100\%. The histogram bin widths are same as those used in Kendon et al. [2014]. 


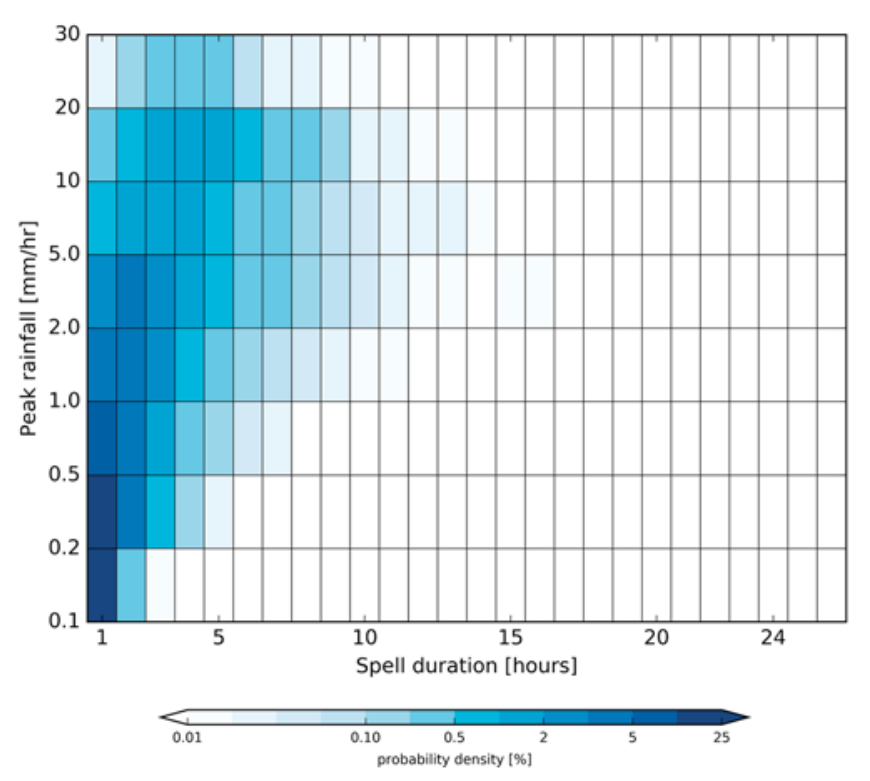

Figure 2. JPDF of wet spell duration and peak rainfall in GPM data over the Northern Plains for summer (June-August) in 2015. The probability of each spell duration-peak rainfall bin is expressed as a percentage between 0 and $100 \%$.

To ensure traceability and reproducibility of the JPDF methodology used in the current study, we distribute the example codes to calculate and plot the JPDF with GPM IMERG data with the Regional Climate Model Evaluation System (RCMES, http://rcmes.jpl.nasa.gov) [Mattmann et al., 2014]. The example source code is accessible in the public repository (https://github.com/apache/climate/blob/master/examples/GPM_WRF24_ JPDF_comparison.py) and executable after installing Open Climate Workbench library version 1.2 (https:// climate.apache.org/). The Jet Propulsion Laboratory and University of California, Los Angeles, have jointly developed RCMES, an evaluation framework for multiscale climate models with a special emphasis on regional and local scales.

To build a climatological JPDF for each data set, we first calculated a regional joint histogram of peak rainfall rate and duration for one summer (JJA). The joint histogram is similar to Figure 2, but a frequency of wet spells is assigned to each bin, not the probability as in the JPDF. After calculating joint histograms in each summer for multiple summers, we divided the sum of the histograms by the total number of wet spells for multiple years to calculate climatological frequency values. Climatological JPDFs for WRF24 and WRF12 and Stage IV were calculated by merging nine joint histograms between 2002 and 2010. WRF04's climatological JPDF is from 5 year JPDFs between 2000 and 2004. With GPM, only the observations in 2014 and 2015 are available to build a JPDF. To measure similarity of a simulated JPDF to an observed JPDF, our model evaluation metric [H. Lee et al., 2015] was calculated as

$$
\text { overlap }=\sum_{x} \sum_{y} \operatorname{minimum}\left(F_{0}(x, y), F_{1}(x, y)\right)
$$

where $x$ is wet spell duration and $y$ is rainfall intensity. $F_{0}$ and $F_{1}$ are JPDFs from observational and model data sets, respectively. The overlap ranges from 0 to $100 \%$, and performance of a simulation is better with larger overlap values. This simple metric measures the similarity between two JPDFs quantitatively. However, there are no predefined benchmark values to measure statistical significance and a $p$ value of the overlap. So the overlap ratios should be used as a relative metric.

\section{Results}

We compared the modeled diurnal cycle of precipitation with that from Stage IV observations. First, we regridded the hourly precipitation from Stage IV, WRF04, and WRF12 into WRF24 grid points before comparing their diurnal cycles with that of WRF24 in summer. Figures $3 a-3 d$ show the regridded precipitation patterns that are temporally averaged over the 276 days (the three summers between 2002 and 2004) for 06 UTC in the Central Plains (the green region in Figure 1). At each of 935 grid points in the Central Plains, we calculated 
(a) Stage IV

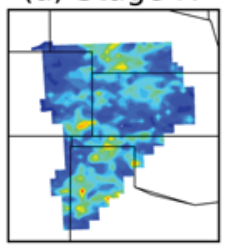

(b) WRF04

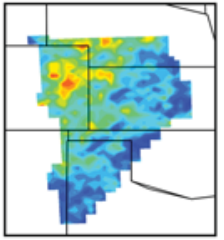

(c) WRF12

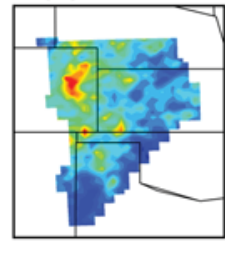

$\frac{1}{0.390 .450 .510 .57}$ (d) WRF24

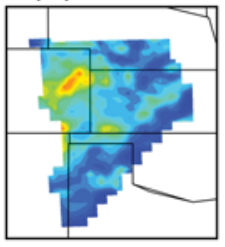

$\begin{array}{lllllllllll}0.03 & 0.09 & 0.15 & 0.21 & 0.27 & 0.33 & 0.39 & 0.45 & 0.51 & 0.57\end{array}$

(e) diurnal cycle of precipitation

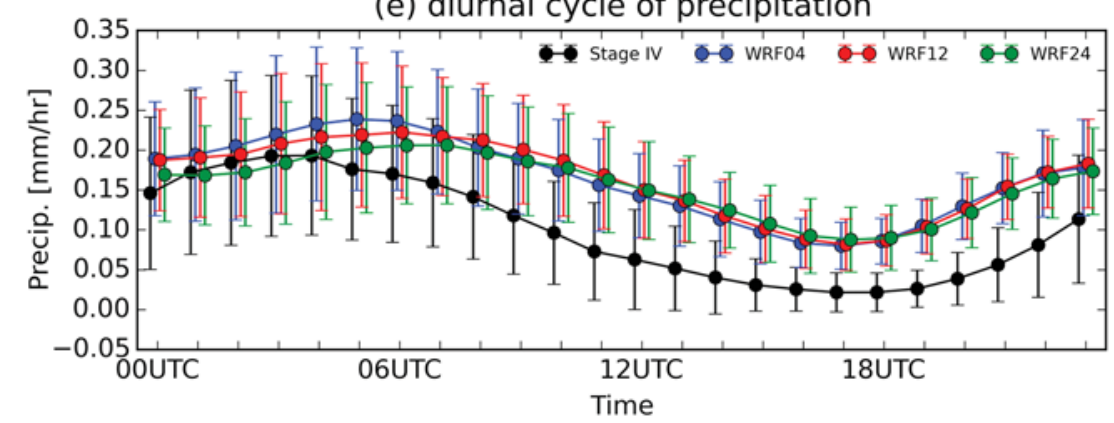

Figure 3. The 3 year (2002-2004) mean summertime (June-August) hourly precipitation for 06 UTC over the Central Plains from (a) Stage IV, (b) WRF04, (c) WRF12, and (d) WRF24. Except WRF24, the data sets are regridded into WRF24 grids. (e) Diurnal cycle of precipitation averaged over the Central Plains for the three summers between 2002 and 2004. The errors bars represent spatial standard deviation of the 3 year mean precipitation for each UTC.

precipitation diurnal cycles averaged over the 276 days using the four hourly precipitation data sets. Figure $3 \mathrm{e}$ displays the spatial mean and standard deviation of the 935 precipitation diurnal cycles in the Central Plains.

The observed precipitation for 06 UTC does not have a noticeable spatial pattern in the region. In contrast, the simulated precipitation is featured by peak precipitation of around $0.35 \mathrm{~mm} / \mathrm{h}$ in Eastern Colorado. In Figure 3e, the three simulations show good agreement in their representation of the nighttime precipitation between 00 and 04 UTC. However, there are differences in the timing of peak precipitation between Stage IV and NU-WRF. The observed precipitation peaks at 04 UTC (10-11 P.M. at local time), whereas NU-WRF simulates the highest precipitation at 06 UTC. The impact of spatial resolution on the regridded hourly precipitation is relatively small compared to the common biases of the three simulations.

Figure 3e provides a concise summary of observed and simulated diurnal cycles of precipitation. However, the large spatial variability displayed with error bars indicates that the spatial mean of the precipitation diurnal cycle does not fully represent the regional precipitation characteristics. So we compared precipitation diurnal cycles between NU-WRF and Stage IV by calculating a bias and an RMSE at each grid point inside our analysis domain. Then we summarized the results by calculating spatial averages of the biases and RMSEs for each of the three regions. WRF-24 has 1829, 935, and 971 grid points in the Northern, Central, and Southern Plains, respectively.

Figure 4 shows biases and RMSEs of the simulations from Stage IV over the Southern Plains. Overall, the agreement between Stage IV and the simulations appears to be good except the southeastern part of the region. As shown in Figure 3, the biases and RMSEs of precipitation diurnal cycle do not show a significant dependence on the spatial resolution of NU-WRF. WRF24's bias and RMSE are smallest in this region. Table 2 lists spatially averaged biases and RMSEs for the three regions. Considering that the data sets are available for 9 years except WRF04, we evaluated the 9 year climatological diurnal cycles from WRF12 and WRF24 as well. The performance difference between the three simulations is smaller than the systematic biases of NU-WRF as shown in Figure 3e. In all three regions, WRF24 shows the best agreement in a diurnal cycle of precipitation with Stage IV. The biases and RMSEs in WRF12 are slightly smaller than those in WRF04 in the Northern and Southern Plains. This indicates that our comparison of the diurnal precipitation cycle does not show the added value of high-resolution dynamical downscaling.

To demonstrate the added value of high-resolution NU-WRF simulations in reproducing hourly precipitation characteristics, we analyzed impacts of (1) spatial resolution, (2) spectral nudging, and (3) cumulus 
(a) bias: WRF04

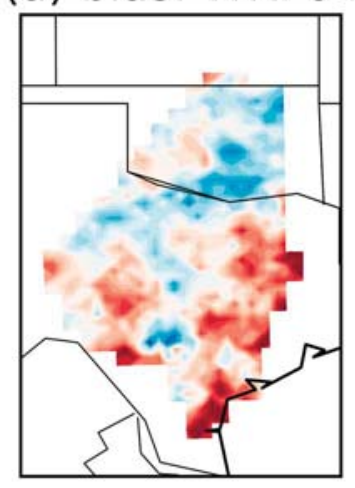

(b) bias: WRF12

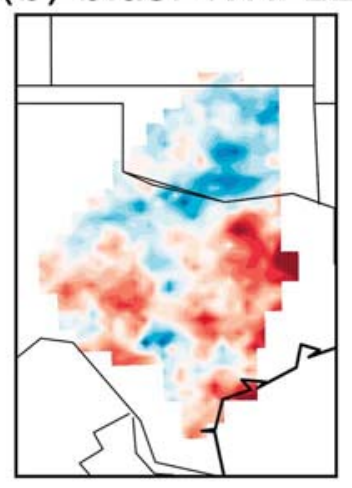

(c) bias: WRF24

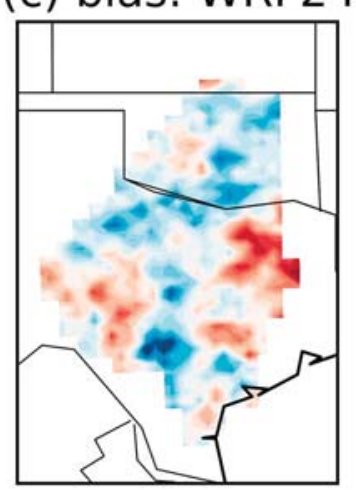

\section{$\begin{array}{lllllll}-0.09 & -0.06 & -0.03 & 0.00 & 0.03 & 0.06 & 0.09\end{array}$}

(d) RMSE: WRF04

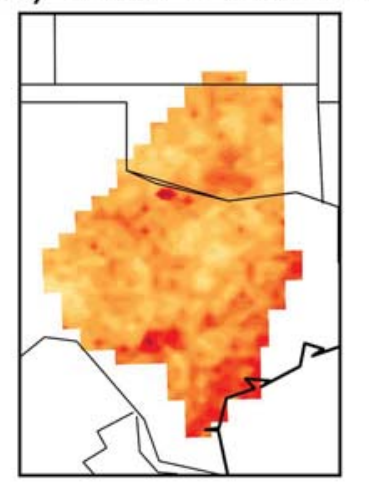

(e) RMSE: WRF12

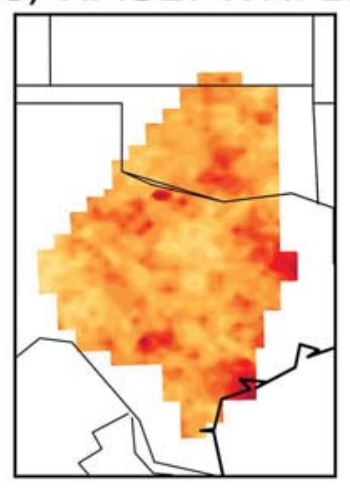

(f) RMSE: WRF24

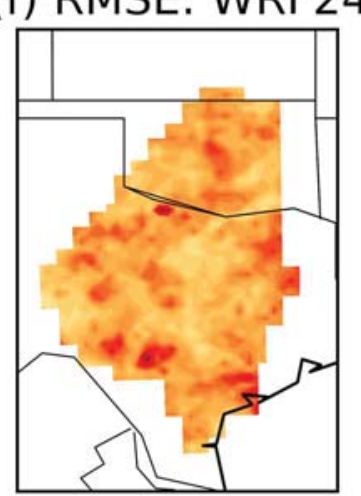

$\begin{array}{llllllllll}0.01 & 0.03 & 0.05 & 0.07 & 0.09 & 0.11 & 0.13 & 0.15 & 0.17 & 0.19\end{array}$

Figure 4. Biases ( $\mathrm{mm} / \mathrm{h}$ ) of precipitation diurnal cycle in (a) WRF04, (b) WRF12, and (c) WRF 24 from Stage IV observations over the Southern Plains. Except WRF24, the data sets are regridded into WRF24 grids. The 3 year (2002-2004) mean diurnal cycle of precipitation is calculated at each grid point. (d-f) Same as Figures $4 a-4 c$ but for root-mean-square errors (RMSEs) in the simulated multiyear mean diurnal cycle of precipitation.

parameterization on the NU-WRF's performance in simulating the JPDFs of wet spell duration and peak intensity. Figure 5 shows the JPDFs from Stage IV, and the biases of three WRF simulations for the Central Plains in summer (JJA). Similar to Figure 2, the majority of rainfall duration is less than $3 \mathrm{~h}$, and hourly peak rainfall is lower than $5 \mathrm{~mm} / \mathrm{hr}$ in most of the rain events in Stage IV. More than 11 million wet spells in Stage IV data sets for 9 years are summarized in Figure 5a; i.e., even a 1\% value in the JPDF accounts for about 100,000 rainfall events occurred in the region. For the simulations shown in Figures $5 b-5 d$, the common negative biases indicate that short-duration downpour events whose peak rainfall is higher than $5 \mathrm{~mm} / \mathrm{h}$ and duration is less than

Table 2. Spatially Averaged Biases and RMSEs of Precipitation Diurnal Cycles for the Three Simulations Against Stage IV Over the Northern, Central, and Southern Plains ${ }^{a}$

\begin{tabular}{lcccccccc} 
& \multicolumn{2}{c}{ Northern Plains } & & \multicolumn{2}{c}{ Central Plains } & & \multicolumn{2}{c}{ Southern Plains } \\
\cline { 2 - 3 } \cline { 8 - 9 } Simulations & Bias & RMSE & & Bias & RMSE & & Bias & RMSE \\
\hline WRF04 & 0.05 & 0.081 & & 0.064 & 0.108 & & 0.0093 & 0.0097 \\
WRF12 & $0.043(0.043)$ & $0.077(0.061)$ & & $0.064(0.047)$ & $0.109(0.078)$ & & $0.0074(0.022)$ & $0.098(0.062)$ \\
WRF24 & $0.034(0.035)$ & $0.073(0.057)$ & & $0.055(0.039)$ & $0.106(0.074)$ & & $-0.0057(0.0072)$ & $0.093(0.054)$ \\
\hline
\end{tabular}

aThe precipitation diurnal cycles are averaged for the three summers between 2002 and 2004 . The numbers in the parentheses are the biases and RMSEs for climatological diurnal cycle averaged for the nine summers between 2002 and 2010. 
(a) Stage IV

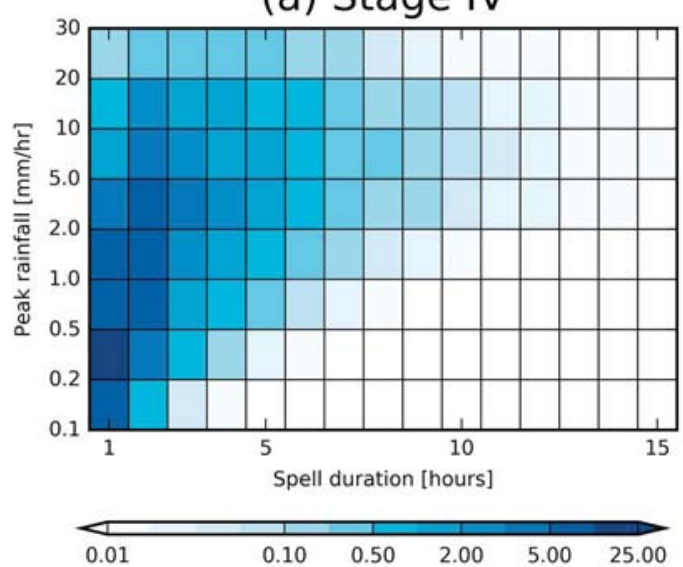

(c) WRF12 - Stage IV

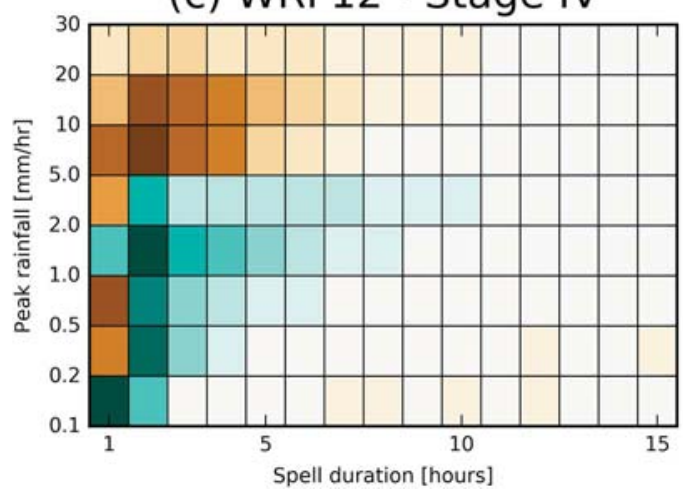

(b) WRF04 - Stage IV

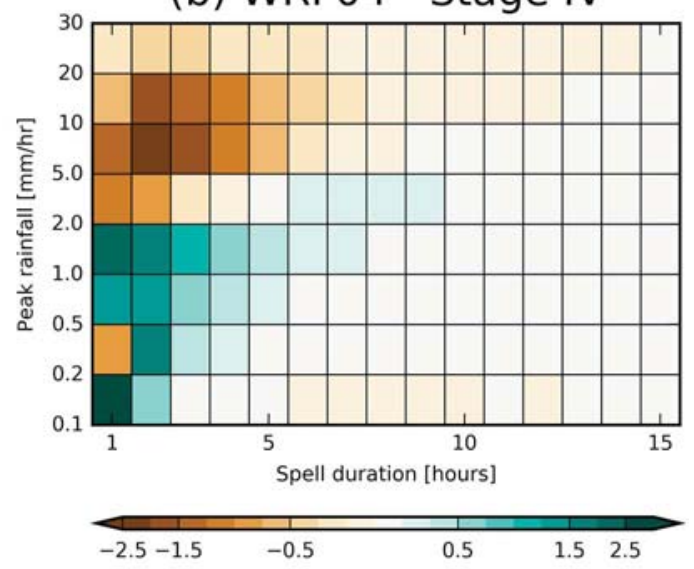

(d) WRF24 - Stage IV

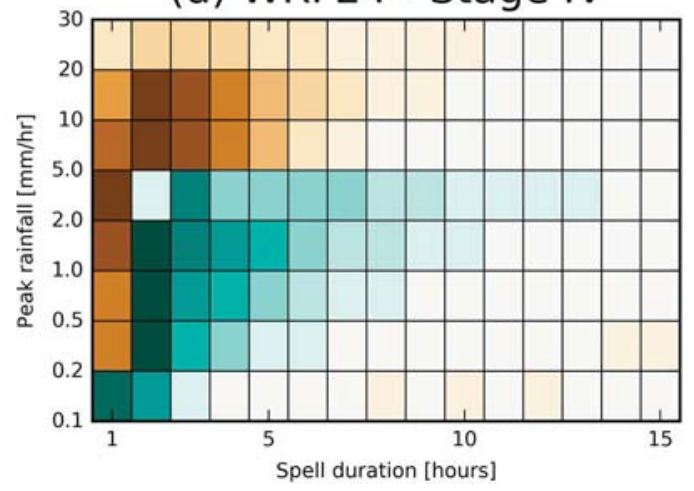

Figure 5. (a) Climatological summertime (June-August) JPDF from hourly Stage IV data over the Central Plains between 2002 and 2010. The color scales probability density (\%) of each bin. The JPDF differences of (b) WRF04, (c) WRF12, and (d) WRF24 simulations with spectral nudging at $600 \mathrm{~km}$ scale from the Stage IV JPDF in Figure 5a.

$5 \mathrm{~h}$ occur less frequently in NU-WRF than Stage IV. The negative bias in short-duration downpours in NU-WRF is a common problem for all three Great Plains regions, regardless of the model's spatial resolution. Also, in NU-WRF, rainfall duration tends to be longer than Stage IV when the peak rainfall is less than $5 \mathrm{~mm} / \mathrm{h}$. The frequency of short-duration downpour events becomes slightly higher with the higher spatial resolution of NU-WRF. As a result, WRF12 shows better agreement with Stage IV than WRF24, and WRF04's performance is the best. The overlap ratios of JPDFs in Table 3 show the quantitative performance of the three NU-WRF simulations. Eighty-one percent of the WRF04 JPDF in Figure 5b overlaps the observed JPDF in Figure 5a, whereas the overlap between Stage IV and WRF24 JPDFS is only $67 \%$.

In Figure 6, the reference data are the JPDF from GPM precipitation for the Southern Plains. Overall, the better performance of WRF04 is consistent with the comparison with Stage IV JPDF for the Central Plains. As expected from the JPDF comparison for the Central Plains, WRF04 better represents wet spells whose peak rainfall is less than $5 \mathrm{~mm} / \mathrm{h}$. The negative biases in WRF12 and WRF24 for the rainfall that lasts less than an hour become weak positive in WRF04. Additionally, there are noticeable improvements in the short-duration downpour rainfall in WRF04 and WRF12 compared to WRF 24. When comparing precipitation whose duration is longer

Table 3. Overlap (\%) of the JPDFs Between NU-WRF Simulations With $600 \mathrm{~km}$ Spectral Nudging and StageIV/GPM in the Northern, Central, and Southern Plains ${ }^{\mathrm{a}}$

\begin{tabular}{lccc} 
Simulations & Northern Plains & Central Plains & Southern Plains \\
\hline WRF04 & $\mathbf{8 4 / 8 2}$ & $\mathbf{8 1 / 7 7}$ & $\mathbf{8 2 / 7 9}$ \\
WRF12 & $79 / 76$ & $78 / 73$ & $74 / 71$ \\
WRF24 & $70 / 67$ & $67 / 62$ & $62 / 59$ \\
\hline
\end{tabular}

${ }^{\mathrm{a}}$ The highest overlap in each region is highlighted in bold. 
(a) GPM

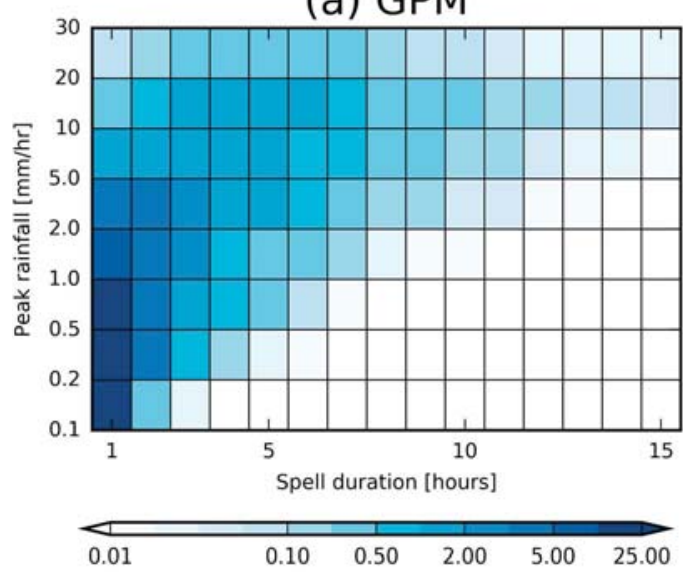

(c) WRF12 - GPM

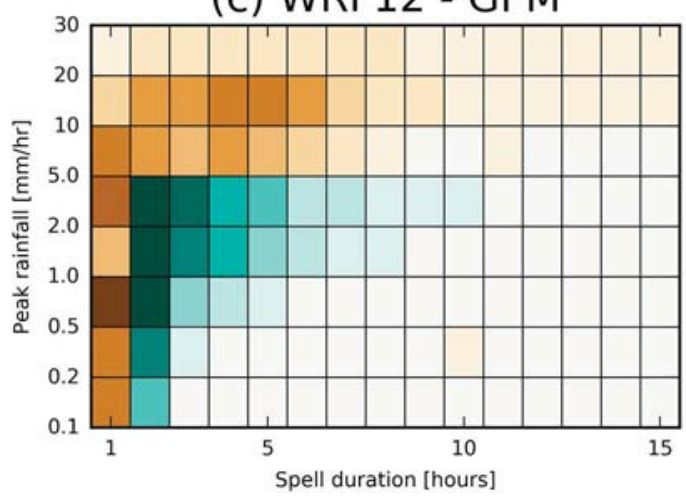

(b) WRF04 - GPM

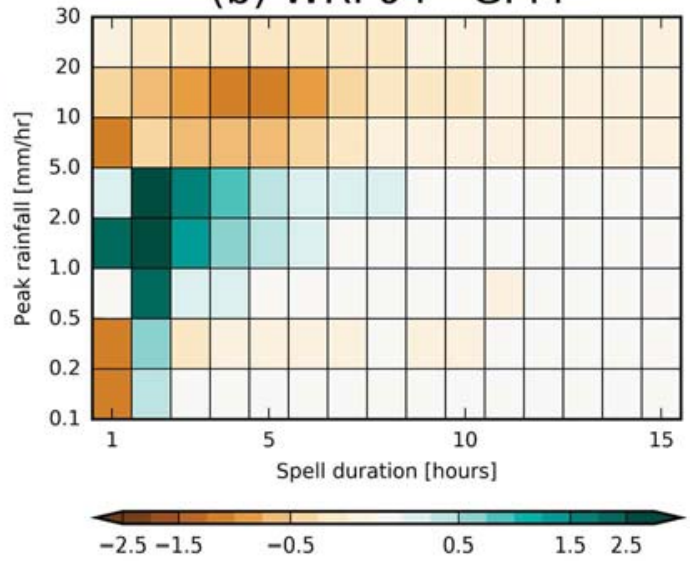

(d) WRF24 - GPM

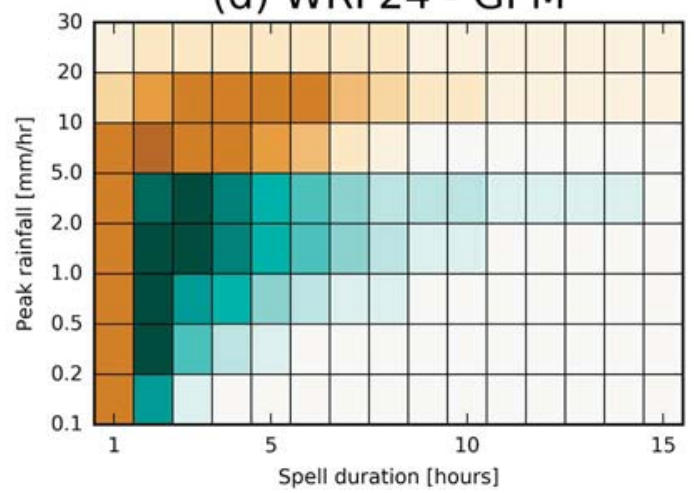

Figure 6. (a) Climatological summertime (June-August) JPDF from hourly GPM data over the Southern Plains between 2014 and 2015. The color scales probability density (\%) of each bin. The JPDF differences of (b) WRF04, (c) WRF12, and (d) WRF24 simulations with spectral nudging at $600 \mathrm{~km}$ scale from the GPM JPDF in Figure 6a.

than $10 \mathrm{~h}$ and intensity is greater than $10 \mathrm{~mm} / \mathrm{h}$, both WRF04 and WRF12 show improvement over WRF24. The performance of WRF12 is slightly better than WRF04 in this precipitation regime. The overlap ratios for WRF04, WRF12, and WRF24 are 79\%, 71\%, and 59\% respectively (Table 3).

In Table 3, it is obvious that the JPDFs from WRF04 show the best agreement with both observed JPDFs in all three regions. The performance of WRF12 is also always better than WRF 24 against the two observational data sets. Our result is consistent with the findings in Sun et al. [2016] who report that more realistic precipitation over the Central Plains in WRF with $4 \mathrm{~km}$ resolution than that in the $25 \mathrm{~km}$ WRF simulation results from the more accurate intensity, location, and diurnal cycle of the low-level jet.

When climate model output is available only for a shorter period than other data sets to compare with, as in our case with WRF04, there is an intrinsic uncertainty in the calculated metric for WRF04 evaluation in Table 3. To estimate the uncertainty of the overlap ratio for the 5 years of WRF04 run, we randomly subsampled 9 years of JPDFs from WRF24 and WRF12 without replacement. The size of samples ranges from one to 8 years. For each sample size, we built climatological JPDF for each region using JPDFs in the subsampled years and calculated the overlap ratio between the subsampled JPDF and Stage IV JPDF. We repeated this subsampling and evaluation process 100 times and defined the standard deviation of the overlap ratio across the 100 subsamples as the uncertainty of the overlap ratio due to the subsampling. The underlying assumption of this Monte Carlo simulation is that the uncertainty of the overlap ratio between WRF04 and Stage IV caused by the WRF04's shorter period than the other data sets can be estimated by comparing the subsampled JPDFs from WRF12 and WRF24 with the 9 year climatological JPDF from Stage IV. The corresponding results are reported in Figure 7. Figure 7a shows that our performance evaluation metric, the overlap ratio between observed and simulated JPDFs, does not have a strong dependence on the number of years sampled. As expected, the uncertainty of the overlap ratios decreases with increasing sample size in Figure $7 \mathrm{~b}$. The similarity of the uncertainty between WRF24 and WRF12 indicates that our assumption to estimate the uncertainty in the metric 
(a) overlap ratio of the sampled JPDFs

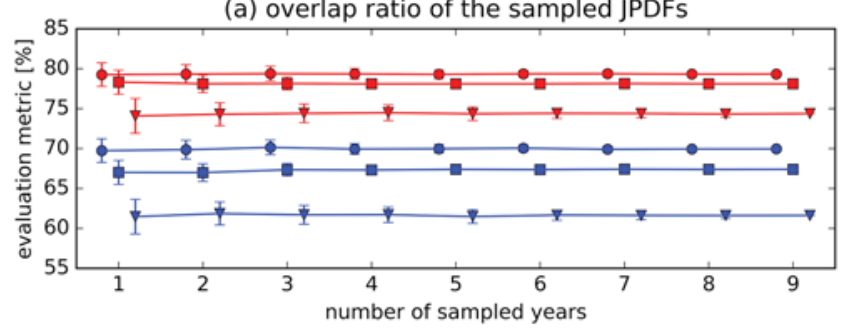

(b) uncertainty of the overlap ratio

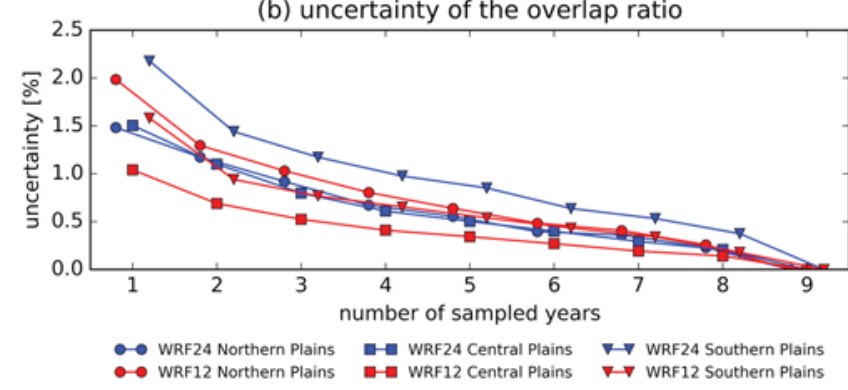

Figure 7. (a) Mean and standard deviation of the overlap ratios between the subsampled JPDFs from (blue: WRF24; red: WRF12) and Stage IV. (b) Standard deviation of the overlap ratios as uncertainty due to the temporal subsampling. for WRF04 using subsampled WRF24 and WRF12 is reasonable. It should be noted that Figure 7 shows the value of highresolution WRF04 data set, even when the overlap ratio is computed using only 5 years of simulated data. The largest uncertainty by subsampling only 1 year of data to build JPDF is less than $2.5 \%$ for both WRF24 and WRF12. Considering the difference in the overlap ratio between WRF04, WRF12, and WRF24 shown in Table 3, WRF04 precipitation, even for the five summers between 2000 and 2004, still provides the most realistic representation of the observed JPDF.

We also tested if the 2 years of GPM data (2014 and 2015) can be used to build JPDFs for model evaluation. The overlap ratios between GPM and Stage IV JPDFs for summer 2014 are 81, 85, and 85\% for the Northern, Central, and Southern Plains, respectively. These overlap ratios are comparable to those for WRF04 in Table 3.

For $24 \mathrm{~km}$ and $12 \mathrm{~km}$ simulations, there are additional runs with a spectral nudging scale of $2000 \mathrm{~km}$ and those without spectral nudging. Table 4 summarizes the impact of spectral nudging scales on the similarity of the simulated JPDFs to Stage IV JPDF. In the Northern Plains, nudged runs show better agreement with the observation for both WRF24 and WRF12. However, it is hard to say that the nudging improves the performance of NU-WRF significantly in simulating rainfall characteristics in the Central and Southern Plains.

Unlike the spectral nudging, the choice of cumulus parameterization used in NU-WRF affects the JPDF over the Great Plains (Table 4). New simplified Arakawa-Schubert scheme shows the best performance overall, followed by the default cumulus parameterization scheme, Grell 3-D ensemble scheme, new Kain-Fritsch scheme, and Bretts-Miller-Janjic scheme. Because the different parameterizations were tested with 24 km resolution only, the performance of cumulus parameterization schemes in Table 4 is not guaranteed in NU-WRF simulations with higher spatial resolution, such as WRF12 and WRF04. Also, it should be noted that Table 4

\begin{tabular}{|c|c|c|c|}
\hline Simulations & Northern Plains & Central Plains & Southern Plains \\
\hline \multicolumn{4}{|c|}{ Spectral Nudging Scales } \\
\hline WRF12 & 79 & 78 & 74 \\
\hline WRF12-2000 & 80 & 79 & 75 \\
\hline WRF12-no-nudging & 74 & 77 & 75 \\
\hline WRF24 & 70 & 67 & 62 \\
\hline WRF24-2000 & 70 & 67 & 62 \\
\hline WRF24-no-nudging & 66 & 68 & 64 \\
\hline \multicolumn{4}{|c|}{ Cumulus Parameterization Schemes } \\
\hline WRF24-BMJ & 57 & 64 & 53 \\
\hline WRF24-NKF & 62 & 58 & 55 \\
\hline WRF24-NSAS & 70 & 72 & 70 \\
\hline
\end{tabular}

${ }^{\mathrm{a}}$ The spectral nudging scale of WRF 12 and WRF 24 is $600 \mathrm{~km}$. 
Table 5. Overlap (\%) of the JPDFs Between Regridded Stage IV and Simulations in the Northern, Central, and Southern Plains ${ }^{a}$

\begin{tabular}{lccc} 
Simulations & Northern Plains & Central Plains & Southern Plains \\
\hline WRF04 & $85(84)$ & $83(81)$ & $83(82)$ \\
WRF12 & $78(79)$ & $79(78)$ & $75(74)$ \\
WRF24 & $74(70)$ & $72(67)$ & $66(62)$ \\
\hline
\end{tabular}

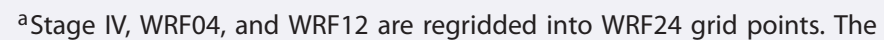
numbers in the parenthesis are from Table 3 for the comparison of the overlap ratios with the original Stage IV JPDF.

shows NU-WRF sensitivity of JPDF to the cumulus parameterization only over the Great Plains in summer. It is hard to find the best parameterization scheme under any conditions. However, it is important to carry out a sensitivity test of cumulus parameterization schemes at a low spatial resolution and use the result as a guide to planning more computationally demanding simulations. Iguchi et al. [2017] provide more detailed analysis of six different cumulus parameterization schemes and their impacts on NU-WRF simulations over CONUS.

Analyzing hourly time series at each grid point and building regional JPDF of precipitation peak intensity and duration may not require regridding to compare with JPDFs from high-resolution observations. However, by using data sets at their original grid points, a data set's horizontal resolution determines the number of samples used for building JPDFs. For example, there are 65,023 Stage IV grid points in the Northern Plains, whereas WRF24 and WRF12 have only 2434 and 9703 grid points from the same region. Considering the difference in sample sizes, we used the Stage IV, WRF04, and WRF12 data sets regridded into WRF24 grid points to build JPDFs. This upscaling approach is same as that of Kendon et al. [2012]. The overlap ratios between the regridded Stage IV and simulations are listed in Table 5. The upscaling via regridding does not significantly change the performance of NU-WRF. The JPDF from the regridded Stage IV has the highest overlap ratio with the regridded WRF04's JPDF. Therefore, spatial regridding does not diminish the added value of high-resolution NU-WRF simulations in terms of JPDFs of summertime precipitation in the Great Plains. The higher overlap ratios in JPDFs between WRF24 and regridded Stage IV than those in Table 3 may result from less number of wet spells from the upscaled Stage IV precipitation data.

We also aggregated the high-resolution Stage IV data into the nearest WRF24 and WRF12 grid points and calculated average precipitation. Then we built another set of JPDFs using the aggregated Stage IV precipitation for the three regions and compared them with those from WRF24 and WRF12. The underlying hypothesis of these data aggregation and averaging processes is that low-resolution WRF simulations may represent spatially averaged fields from their high-resolution counterparts. Not surprisingly, WRF 24 and WRF12 show better agreement with the JPDF from the spatially aggregated Stage IV than the comparison with the JPDF from original Stage IV data. The agreement in Table 6 is comparable to the overlap ratios for WRF04 in Table 3. Nevertheless, this does not mean that we need to regrid or aggregate high-resolution observation data into coarse model grid points. The spatial aggregation smoothens fine-scale spatial patterns of precipitation that also have a high temporal frequency. When comparing JPDFs made out of 3-hourly precipitation data sets from Stage IV and the NU-WRF simulations, WRF04 does not show noticeable improvement over WRF12 and WRF24 (not shown). In addition, other precipitation data sets whose temporal resolutions are 3-hourly or daily could not clearly demonstrate the advantage of WRF04 over WRF12 and WRF24. This further suggests that we may need to use the GPM IMERG data set with its original half-hourly resolution when evaluating JPDFs from RCM simulations whose resolution is higher than $4 \mathrm{~km}$.

\begin{tabular}{|c|c|c|c|}
\hline Simulations & Northern Plains & Central Plains & Southern Plains \\
\hline WRF12 & $85(79)$ & $82(78)$ & 79 (74) \\
\hline WRF24 & $82(70)$ & $82(67)$ & $77(62)$ \\
\hline
\end{tabular}


(a) GPM precipitation

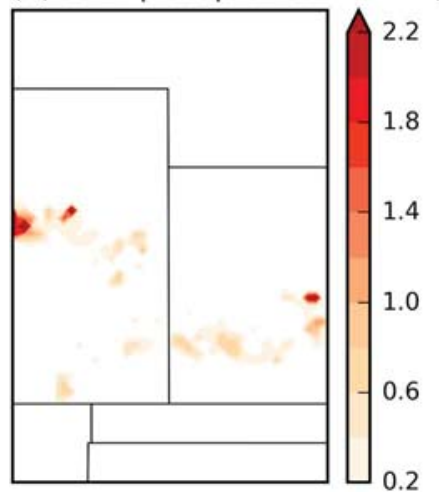

(b) aggregated precipitation

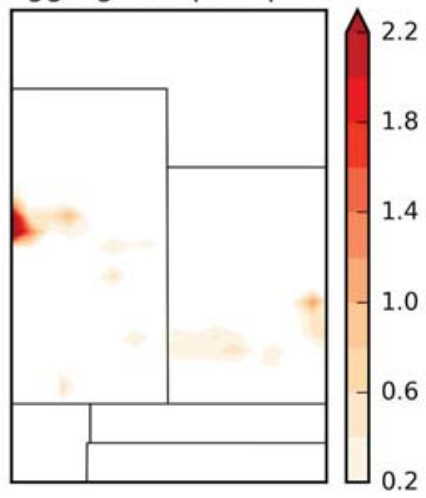

(c) fine-scale pattern

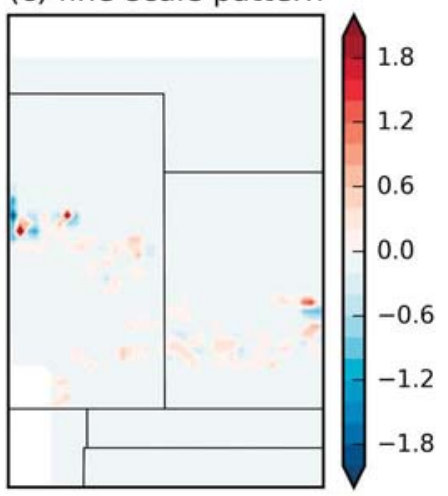

Figure 8. (a) GPM precipitation over Nebraska, Colorado, Kansas, and Oklahoma Panhandle recorded at 1:30 UTC, 8 July 2014. (b) Spatially aggregated GPM precipitation into WRF24 grid points. (c) Fine-scale spatial pattern of the precipitation after subtracting Figure $8 \mathrm{~b}$ from Figure $8 \mathrm{a}$.

\section{Discussion and Conclusions}

The JPDF of precipitation peak intensity and duration provides a summary of hourly precipitation data over a region of interest. By calculating the JPDF, we can reduce the data size substantially while still maintaining the key information including the intensity and duration of extreme precipitation events whose frequency highly depends on data set's resolution. Therefore, the JPDF and our quantitative evaluation metric, the overlap ratio between two JPDFs, can be useful to assess the regional variability of extreme precipitation under a changing climate.

Our evaluation of simulated diurnal cycle in precipitation over the U.S. Great Plains does not provide any evidence to support the added value of NU-WRF simulations with fine spatial resolutions. However, our evaluation of the simulated JPDFs demonstrates the added value in reproducing hourly precipitation characteristics in the Great Plains of the United States and complements many previous studies that focus on the improvement of topographical precipitation obtained by dynamical downscaling.

The three NU-WRF simulations (WRF24, WRF12, and WRF04) commonly show less frequent short-duration downpour events in all three regions. Nevertheless, the NU-WRF with $4 \mathrm{~km}$ resolution simulates the most similar rainfall characteristics to Stage IV and GPM at its original grid points. The overlap ratios between WRF04 and the observations are similar to those within the observations. Therefore, the added value of NU-WRF simulations with higher resolution is a more realistic precipitation over the Great Plains in summer. The choice of spectral nudging does not have a significant impact on the precipitation JPDF over the Great Plains. The effect of cumulus parameterization schemes is considerable but smaller than the improvement of NU-WRF simulations due to high spatial resolution.

WRF04's value is allowing us to fully utilize high-resolution observation data sets such as Stage IV and GPM without regridding them. Figure 8a shows a snapshot of GPM precipitation at 0130 UTC on 8 July 2014 over Nebraska, Colorado, Kansas, and Oklahoma Panhandle. When we spatially aggregate the GPM precipitation at the resolution of $0.1^{\circ}$ into WRF24's grid points at $24 \mathrm{~km}$ resolution, we lose a significant fraction of the information contained in the original GPM data. As shown in Figure $8 \mathrm{~b}$, the upscaled map of precipitation is different from the original one. The fine-scale spatial pattern in Figure $8 \mathrm{c}$ could be another benefit of using high-resolution data sets, such as GPM and WRF04 results. In other words, the added value of high-resolution simulations is equivalent to lost information when spatially averaging high-resolution data. Wang et al. [2015] also report that high spatial resolution allows dynamically downscaled simulations to capture spatiotemporal relationships of precipitation occurrence in high-resolution observations.

Finally, our results indicate that without the full 11 years (2000-2010) of simulations or observations, we can still show the added value of WRF04 simulation with some uncertainty due to the temporal subsampling. However, if available computational resources were not limited, we could obtain more realistic JPDFs with an extended WRF04 simulation. 


\section{Acknowledgments}

This work was performed at the Jet Propulsion Laboratory, California Institute of Technology, under contract with NASA. We thank Tsengdar Lee at the NASA Headquarters for leading the NASA downscaling project. The two observational data sets, Stage IV (http://www.emc.ncep.noaa.gov/ $\mathrm{mmb} / \mathrm{lin} /$ pcpanl/stage4/) and GPM (https://pmm.nasa.gov/data-access/ downloads/gpm), were obtained freely online. The NU-WRF simulation data can be accessed via the supercomputers managed by NASA Center for Climate Simulation (NCCS, https://www.nccs.nasa.gov/) after obtaining a NCCS account. Copyright 2017. All rights reserved.

\section{References}

Ban, N., J. Schmidli, and C. Schär (2015), Heavy precipitation in a changing climate: Does short-term summer precipitation increase faster?, Geophys. Res. Lett., 42(4), 1165-1172, doi:10.1002/2014GL062588.

Bosilovich, M. G., et al. (2015), MERRA-2: Initial evaluation of the climate, NASA/TM-2015-104606/Vol. 43, Global Modeling and Assimilation Office, Greenbelt, Md. [Available at https://gmao.gsfc.nasa.gov/reanalysis/MERRA-2/docs/, accessed 10 July 2017.]

Bukovsky, M. S. (2011), Masks for the bukovsky regionalization of North America, Regional Integrated Sciences Collective. Institute for Mathematics Applied to Geosciences, National Center for Atmospheric Research, Boulder, Colo. [Available at http://www.narccap.ucar.edu/contrib/bukovsky/, accessed 10 July 2017.]

Casanueva, A., et al. (2016), Daily precipitation statistics in a EURO-CORDEX RCM ensemble: Added value of raw and bias-corrected high-resolution simulations, Clim. Dyn., 47(3-4), 719-737, doi:10.1007/s00382-015-2865-x.

Chan, S. C., E. J. Kendon, H. J. Fowler, S. Blenkinsop, N. M. Roberts, and C. A. T. Ferro (2014), The value of high-resolution met office regional climate models in the simulation of multihourly precipitation extremes, J. Clim., 27(16), 6155-6174, doi:10.1175/Jcli-D-13-00723.1.

Cortes-Hernandez, V. E., F. F. Zheng, J. Evans, M. Lambert, A. Sharma, and S. Westra (2016), Evaluating regional climate models for simulating sub-daily rainfall extremes, Clim. Dyn., 47(5-6), 1613-1628, doi:10.1007/s00382-015-2923-4.

De Sales, F., and Y. Xue (2011), Assessing the dynamic-downscaling ability over South America using the intensity-scale verification technique, Int. J. Climatol., 31(8), 1205-1221, doi:10.1002/joc.2139.

Di Luca, A., R. de Elia, and R. Laprise (2012), Potential for added value in precipitation simulated by high-resolution nested regional climate models and observations, Clim. Dyn., 38(5-6), 1229-1247.

Donat, M. G., A. L. Lowry, L. V. Alexander, P. A. O'Gorman, and N. Maher (2016), More extreme precipitation in the world's dry and wet regions, Nat. Clim. Change, 6(5), 508-513, doi:10.1038/Nclimate2941.

Ferraro, R., D. Waliser, and C. Peters-Lidard, (2017), NASA downscaling project final report, NASA Tech. Rep. NASA/TM-2017-219579, Jet Propulsion Laboratory, Pasadena, Calif. [Available at https://trs.jpl.nasa.gov/handle/2014/45705, accessed on 10 July 2017.$]$

Feser, F., B. Rockel, H. von Storch, J. Winterfeldt, and M. Zahn (2011), Regional climate models add value to global model data a review and selected examples, Bull. Am. Meteorol. Soc., 92(9), 1181 -1192, doi:10.1175/2011 bams3061.1.

Grell, G. A. (1993), Prognostic evaluation of assumptions used by cumulus parameterizations, Mon. Weather Rev., 121(3), 764-787, doi:10.1175/1520-0493(1993)121<0764:Peoaub>2.0.Co;2.

Grell, G. A., and D. Devenyi (2002), A generalized approach to parameterizing convection combining ensemble and data assimilation techniques, Geophys. Res. Lett., 29(14), 1693, doi:10.1029/2002GL015311.

Groisman, P. Y., R. W. Knight, and T. R. Karl (2012), Changes in intense precipitation over the central United States, J. Hydrometeorol., 13(1), 47-66, doi:10.1175/Jhm-D-11-039.1.

Hall, A. (2014), Projecting regional change, Science, 346(6216), 1461-1462, doi:10.1126/science.aaa0629.

Han, J., and H. L. Pan (2011), Revision of convection and vertical diffusion schemes in the NCEP global forecast system, Weather Forecasting, 26(4), 520-533, doi:10.1175/Waf-D-10-05038.1.

Harding, K. J., P. K. Snyder, and S. Liess (2013), Use of dynamical downscaling to improve the simulation of central US warm season precipitation in CMIP5 models, J. Geophys. Res. Atmos., 118(22), 12,522-12,536, doi:10.1002/2013JD019994.

Hong, S. Y., and M. Kanamitsu (2014), Dynamical downscaling: Fundamental issues from an NWP point of view and recommendations, Asia Pacific J. Atmos. Sci., 50(1), 83-104, doi:10.1007/s13143-014-0029-2.

Huffman, G. J., D. T. Bolvin, D. Braithwaite, K. Hsu, R. Joyce, C. Kidd, E. J. Nelkin, and P. Xie (2015), Nasa global precipitation measurement (gpm) integrated multi-satellite retrievals for gpm (imerg), ATBD Version 4.5, Goddard Space Flight Center, Greenbelt, Md. [Available at https://pmm.nasa.gov/sites/default/files/document_files/IMERG_ATBD_V4.5.pdf, accessed 10 July 2017.]

Iguchi, T., et al. (2017), Sensitivity of CONUS summer Rainfall to the Selection of Cumulus Parameterization Schemes in NU-WRF Seasonal Simulations, J. Hydrometeorol, 18(6), 1689-1706, doi:10.1175/JHM-D-16-0120.1.

Janjic, Z. I. (1994), The step-mountain eta coordinate model - Further developments of the convection, viscous sublayer, and turbulence closure schemes, Mon. Weather Rev., 122(5), 927-945, doi:10.1175/1520-0493(1994)122<0927:Tsmecm>2.0.Co;2.

Janssen, E., D. J. Wuebbles, K. E. Kunkel, S. C. Olsen, and A. Goodman (2014), Observational- and model-based trends and projections of extreme precipitation over the contiguous United States, Earths Future, 2(2), 99-113, doi:10.1002/2013EF000185.

Janssen, E., R. L. Sriver, D. J. Wuebbles, and K. E. Kunkel (2016), Seasonal and regional variations in extreme precipitation event frequency using CMIP5, Geophys. Res. Lett., 43(10), 5385-5393, doi:10.1002/2016GL069151.

Ji, F., M. Ekstrom, J. P. Evans, and J. Teng (2014), Evaluating rainfall patterns using physics scheme ensembles from a regional atmospheric model, Theor. Appl. Climatol., 115(1-2), 297-304, doi:10.1007/s00704-013-0904-2.

Kain, J. S. (2004), The Kain-Fritsch convective parameterization: An update, J. Appl. Meteorol., 43(1), 170-181, doi:10.1175/1520-0450(2004)043<0170:Tkcpau>2.0.Co;2.

Karl, T. R., and R. W. Knight (1998), Secular trends of precipitation amount, frequency, and intensity in the United States, Bull. Am. Meteorol. Soc., 79(2), 231-241, doi:10.1175/1520-0477(1998)079<0231:Stopaf>2.0.Co;2.

Kendon, E. J., N. M. Roberts, C. A. Senior, and M. J. Roberts (2012), Realism of rainfall in a very high-resolution regional climate model, J. Clim., 25(17), 5791-5806, doi:10.1175/Jcli-D-11-00562.1.

Kendon, E. J., N. M. Roberts, H. J. Fowler, M. J. Roberts, S. C. Chan, and C. A. Senior (2014), Heavier summer downpours with climate change revealed by weather forecast resolution model, Nat. Clim. Change, 4(7), 570-576, doi:10.1038/nclimate2258.

Kim, J., et al. (2017), Winter precipitation characteristics in western US related to atmospheric river landfalls: Observations and model evaluations, Clim. Dyn., doi:10.1007/s00382-017-3601-5.

Kumar, S. V., et al. (2006), Land information system: An interoperable framework for high resolution land surface modeling, Environ. Modell. Softw., 21(10), 1402-1415.

Kunkel, K. E., D. R. Easterling, K. Redmond, and K. Hubbard (2003), Temporal variations of extreme precipitation events in the United States: 1895-2000, Geophys. Res. Lett., 30(17), 1900, doi:10.1029/2003GL018052.

Lang, S., W. K. Tao, R. Cifelli, W. Olson, J. Halverson, S. Rutledge, and J. Simpson (2007), Improving simulations of convective systems from TRMM LBA: Easterly and westerly regimes, J. Atmos. Sci., 64(4), 1141-1164.

Lang, S. E., W. K. Tao, X. P. Zeng, and Y. P. Li (2011), Reducing the biases in simulated radar reflectivities from a bulk microphysics scheme: Tropical convective systems, J. Atmos. Sci., 68(10), 2306-2320, doi:10.1175/Jas-D-10-05000.1.

Laprise, R., R. de Elia, D. Caya, S. Biner, P. Lucas-Picher, E. Diaconescu, M. Leduc, A. Alexandru, L. Separovic, and C. N. R. Climate (2008), Challenging some tenets of regional climate modelling, Meteorol. Atmos. Phys., 100(1-4), 3-22, doi:10.1007/s00703-008-0292-9.

Lee, H., J. Kim, D. E. Waliser, P. C. Loikith, C. A. Mattmann, and S. McGinnis (2015), Using joint probability distribution functions to evaluate simulations of precipitation, cloud fraction and insolation in the North America Regional Climate Change Assessment Program (NARCCAP), Clim. Dyn., 45(1-2), 309-323, doi:10.1007/s00382-014-2253-y. 
Lee, J. W., and S. Y. Hong (2014), Potential for added value to downscaled climate extremes over Korea by increased resolution of a regional climate model, Theor. Appl. Climatol., 117(3-4), 667-677, doi:10.1007/s00704-013-1034-6.

Lee, J. W., S. Ham, S. Y. Hong, K. Yoshimura, and M. Joh (2014a), Future changes in surface runoff over Korea projected by a regional climate model under A1B scenario, Adv. Meteorol., 2014, 753790, doi:10.1155/2014/753790.

Lee, J. W., S. Y. Hong, E. C. Chang, M. S. Suh, and H. S. Kang (2014b), Assessment of future climate change over East Asia due to the RCP scenarios downscaled by GRIMS-RMP, Clim. Dyn., 42(3-4), 733-747, doi:10.1007/s00382-013-1841-6.

Lee, J. W., S. Y. Hong, J. E. E. Kim, K. Yoshimura, S. Ham, and M. Joh (2015), Development and implementation of river-routing process module in a regional climate model and its evaluation in Korean river basins, J. Geophys. Res. Atmos., 120(10), 4613-4629, doi:10.1002/2014JD022698.

Leung, L. R., L. O. Mearns, F. Giorgi, and R. L. Wilby (2003), Regional climate research — Needs and opportunities, Bull. Am. Meteorol. Soc., 84(1), 89-95, doi:10.1175/Bams-84-1-89.

Lin, Y. (2011), Gcip/eop surface: Precipitation ncep/emc 4km gridded data (grib) stage iv data. version 1.0., ucar/ncar - earth observing laboratory., Boulder, Colo. [Available at http://data.eol.ucar.edu/dataset/21.093, accessed 10 July 2017.]

Lucas-Picher, P., M. Wulff-Nielsen, J. H. Christensen, G. Adalgeirsdottir, R. Mottram, and S. B. Simonsen (2012), Very high resolution regional climate model simulations over Greenland: Identifying added value, J. Geophys. Res., 117, D02108, doi:10.1029/2011JD016267.

Chou, M.-D., and M. J. Suarez, (1999), A solar radiation parameterization for atmospheric studies, vol. 15, NASA Goddard Space Flight Center, Greenbelt, Md.

Chou, M.-D., and M. J. Suarez, (2001), A thermal infrared radiation parameterization for atmospheric studies, NASA Tech. Rep. NASA/TM-2001-104606, vol. 19, NASA Goddard Space Flight Center, Greenbelt, Md.

Maraun, D., et al. (2010), Precipitation downscaling under climate change: Recent developments to bridge the gap between dynamical models and the end user, Rev. Geophys., 48, RG3003, doi:10.1029/2009RG000314.

Mattmann, C. A., et al. (2014), Cloud computing and virtualization within the regional climate model and evaluation system, Earth Sci. Inform., 7(1), 1-12, doi:10.1007/s12145-013-0126-2.

Min, S. K., X. Zhang, F. W. Zwiers, and G. C. Hegerl (2011), Human contribution to more-intense precipitation extremes, Nature, 470(7334), 378-381, doi:10.1038/nature09763.

Peters-Lidard, C. D., et al. (2015), Integrated modeling of aerosol, cloud, precipitation and land processes at satellite-resolved scales, Environ. Modell. Softw., 67, 149-159, doi:10.1016/j.envsoft.2015.01.007.

Pieri, A. B., J. von Hardenberg, A. Parodi, and A. Provenzale (2015), Sensitivity of precipitation statistics to resolution, microphysics, and convective parameterization: A case study with the high-resolution WRF climate model over Europe, J. Hydrometeorol., 16(4), 1857-1872, doi:10.1175/jhm-d-14-0221.1.

Santanello, J. A., S. V. Kumar, C. D. Peters-Lidard, K. Harrison, and S. J. Zhou (2013), Impact of land model calibration on coupled land-atmosphere prediction, J. Hydrometeorol., 14(5), 1373-1400.

Skamarock, W. C., J. B. Klemp, J. Dudhia, D. O. Gill, D. M. Barker, M. G. Duda, X.-Y. Huang, W. Wang, and J. G. Powers (2008), A description of the advanced research WRF version 3, NCAR Tech. Note NCAR/TN-475+STR, National Center for Atmospheric Research, Boulder, Colo.

Sun, X., M. Xue, J. Brotzge, R. A. McPherson, X.-M. Hu, and X.-Q. Yang (2016), An evaluation of dynamical downscaling of Central Plains summer precipitation using a WRF-based regional climate model at a convection-permitting $4 \mathrm{~km}$ resolution, J. Geophys. Res. Atmos., 121, 13,801-13,825, doi:10.1002/2016JD024796.

Tao, W. K., et al. (2003), Microphysics, radiation and surface processes in the Goddard Cumulus Ensemble (GCE) model, Meteorol. Atmos. Phys., 82(1-4), 97-137.

Tao, W. K., D. Wu, T. Matsui, C. Peters-Lidard, S. Lang, A. Hou, M. Rienecker, W. Petersen, and M. Jensen (2013), Precipitation intensity and variation during MC3E: A numerical modeling study, J. Geophys. Res. Atmos., 118, 7199-7218, doi:10.1002/jgrd.50410.

Wang, J. L., F. N. U. Swati, M. L. Stein, and V. R. Kotamarthi (2015), Model performance in spatiotemporal patterns of precipitation: New methods for identifying value added by a regional climate model, J. Geophys. Res. Atmos., 120, 1239-1259, doi:10.1002/2014JD022434.

Wehner, M. F. (2013), Very extreme seasonal precipitation in the NARCCAP ensemble: Model performance and projections, Clim. Dyn., 40(1-2), 59-80, doi:10.1007/s00382-012-1393-1. 